Ann. Biol. anim. Bioch. Biophys., I976, 16 (2), I55-I58.

NOTE

\title{
INCORPORATION DES ACIDES GRAS \\ A NOMBRE IMPAIR DE CARBONE (15 et 17) DANS LES LIPIDES DE L'CEUF ET DU TISSU ADIPEUX DE LA POULE
}

\author{
B. LECLERCQ \\ avec la collaboration de Marie-Rose Salichon \\ Station de Recherches avicoles, \\ Centre de Recherches de Tours, I. N. R. A., \\ Nouzilly, 37380 Monnaie

\section{RÉSUMÉ}

Ingérés par la. Poule pondeuse, les acides gras à nombre impair de carbone ( 15 et 17 ) contenus dans la levure d'alcanes sont incorporés dans les lipides de l'œuf et ceux du tissu adipeux. Leur taux apparent de transfert est élevé.

\section{INTRODUCTION}

La composition en acides gras des lipides alimentaires peut influencer celle de l'œuf selon la nature des acides gras ingérés (CALET, I959; LECLERCQ, 1974). En général les principales modifications concernent les acides insaturés, les substitutions ayant lieu entre les acides oléique et palmitoléique d'une part et l'acide linoléique d'autre part. L'incorporation à l'œuf d'acides gras non synthétisables par la Poule varie beaucoup selon la formule chimique de cet acide. Ainsi l'acide élaïdique, isomère trans de l'acide oléique s'incorpore très aisément aux lipides de la Poule (Leclerce, I965); il en est de même de l'acide linoléique (Diser, 1964). Au contraire l'acide érucique n'est guère déposé dans l'œuf (LECLERCQ, rg68). On peut se demander ce qu'il en est des acides gras saturés ou insaturés dont la chaîne carbonée renferme un nombre impair d'atomes de carbone et que l'on rencontre dans les lipides de levures cultivées sur alcanes. Tel est l'objet du présent travail. 


\section{MATÉRIEL, E'T MÉTHODES}

Les œufs sont prélevés au cours d'une expérimentation dont l'objet est d'apprécier l'efficacité alimentaire des levures d'alcanes chez la Poule pondeuse. Depuis leur naissance les animaux ont consommé dans leur régime 0 , ro ou $20 \mathrm{p}$. roo de levure. Les prélèvements sont effectués après 4 mois de ponte. On procède aussi à l'ablation de $1 \mathrm{~g}$ de tissu adipeux intra-péritonéal après laparotomie.

Les lipides de la levure sont extraits selon la méthode de DeLPECH et al. (I966) ; ceux de l'œuf et du tissu adipeux par le mélange chloroforme-méthanol selon la méthode de Folch. Obtenus par transméthylation grâce au mélange méthanol-acide sulfurique-benzène (90-5-5) les esters méthyliques sont purifiés par chromatographie en couche mince de gel de silice. Ils sont ensuite séparés et dosés par chromatographie en phase gazeuse dans un chromatographe Varian 1440 muni d'une colonne de $3 \mathrm{~m}$ de longueur et $\mathrm{r} / 8^{\mathrm{c}}$ de pouce de section, remplie de chromosorb 200 mesh imprégné de DEGS. Certains esters méthyliques présentent des temps de rétention très semblables et ne peuvent être distingués de cette façon ; c'est le cas en particulier de l'acide stéarique $(\mathrm{I} 8 ;$ o) et de l'acide heptadécadiénoïque $(\mathrm{I} 7: 2)$. On a alors recours à la chromatographie en couche mince de gel de silice imprégné de nitrate d'argent pour séparer les esters saturés et les diènes. On procède à l'analyse séparée de ces deux séries d'esters par chromatographie en phase gazeuse. La proportion d'acide stéarique est obtenue en utilisant comme référence l'acide margarique (I $7: 0)$, celle de l'acide heptadécadiénoïque $\left(I_{7}: 2\right)$ par rapport à l'acide linoléique $(18: 2)$. D'une manière générale l'identification des acides gras inhabituels est basée sur leur temps de rétention en référence à ceux des acides gras connus et sur leur migration en chromatographie en couche mince sur gel de silice imprégné de nitrate d'argent qui renseigne sur le nombre de doubles liaisons. Quelques analyses complémentaires sont effectuées sur colonnes capillaires de carbowax en vue de détecter la présence éventuelle d'acides gras impair de forme "iso ".

\section{RÉSULTATS ET CONCLUSION}

La composition en acides gras de la levure figure dans le tableau. Cette levure contient 7,2 p. Ioo de matières grasses dont 48,5 p. Ioo sont représentés par des acides gras, soit une teneur de $3,5 \mathrm{p}$. Ioo d'acides gras dans la levure.

La composition des lipides de l'œuf et de ceux des réserves corporelles en acides gras est rapportée dans le même tableau. Les principales modifications enregistrées dans l'œuf sont : l'apparition des acides gras à nombre impair de carbone ( I $_{5}$ et I $_{7}$ ) qu'ils soient saturés ou non, une légère diminution des teneurs en acides palmitique et stéarique. Ces modifications sont presque proportionnelles à la teneur du régime en levure.

Dans le tissu adipeux les mêmes constatations peuvent être faites. De plus les teneurs des acides impairs sont voisines de celles observées dans l'œuf.

Le taux apparent de transfert (quantité d'un acide gras exporté par jour dans le vitellus rapportée à la quantité ingérée chaque jour) des acides gras impairs paraît élevé. Dans le cas, par exemple, de l'acide heptadécanoïque ( $7:$ I) le taux de transfert est de $66 \mathrm{p}$. Ioo avec le régime contenant $20 \mathrm{p}$. Ioo de levure. Pour les autres acides gras les taux de transfert doivent être du même ordre puisque leurs concentrations sont dans les mêmes proportions relatives dans la levure et dans l'œuf. Ces calculs reposent sur l'hypothèse selon laquelle les acides gras impairs ne subissent aucune transformation (désaturation, élongation de chaîne...).

Quoi qu'il en soit nos résultats montrent que, comme chez les mammifères (Van Itallie et Khacha Durian, r969), les acides gras à chaîne impaire peuvent être déposés dans les tissus de réserves. De plus ils s'incorporent aux lipides de l'œuf avec une grande efficacité. Cette incorporation n'entraîne aucun changement important de la concentration des autres acides gras. Par ailleurs la ponte des poules et l'éclosivité des œufs n'étant pas modifiées par l'ingestion de 


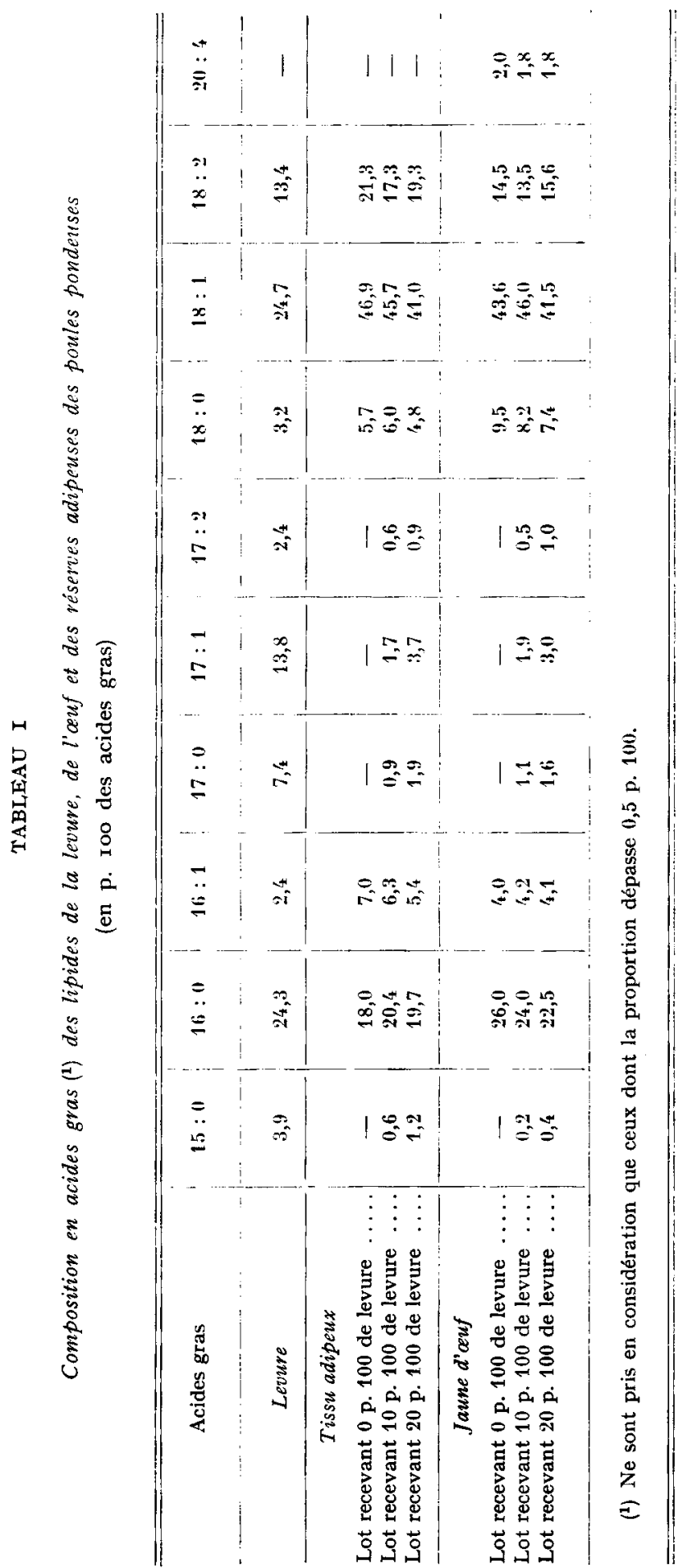


levure (résultats non publiés) on peut penser que chez la Poule comme chez les nammifères (CAMPBell et Hashim, 1969) le métabolisme de l'animal n'est guère modifié par l'ingestion de ces acides gras inhabituels.

Reçu pour publication en août 1975.

\section{REMERCIEMENTS}

Nous tenons à remercier MM. Boudon et JAçues de la Station de Nutrition du C. N. R. Z. de Jouy en Josas qui ont effectué les dosages chromatographiques sur colonnes capillaires.

\section{SUMMARY}

\section{INCORPORATION OF ODD-NUMBERED CARBON FATTY ACIDS (I5 AND I7) IN LIPIDS OF EGG AND ADIPOSE TISSUE OF HEN}

When ingested by laying hen, odd-numbered fatty acids ( 15 and $\mathrm{I} 7$ ) found in alkane yeasts are incorporated into the lipids of egg and adipose tissue. The apparent transfer rate is high.

\section{RÉFÉRENCES BIBIIOGRAPHIQUES}

CALET C., I959. Données nouvelles sur l'influence de l'alimentation sur la quantité et la composition des lipides de l'œuf. Ann. Nutr. Alim., 13, A I63-A 205.

Campbell R. G., Hashim S. A., ig69. Deposition in adipose tissue and transport of odd-numbered fatty acids. Amer. J. Physiol., 217, I6r4-1618.

Delpech P., Guezel M., Leclerce B., Kahane E., I966. Méthode d'extraction des lipides en continu et à chaud par le mélange azéotrope : benzène-éthanol-eau. Rev. Fr. Corps gras, 10, 6I5-620. Diser G., I964. Effect of feeding fatty acids to poultry. World Poult. Sci. J., 20, 26-40.

LECLERCQ B., BLUM J. C., JACQUOT R., I965. Étude de l'utilisation de l'acide élaïdique au cours de l'ovogenèse de Gallus gallus: son incorporation dans les graisses de réserves et dans les lipides de l'œuf pondu. C. R. Acad. Sci., 261, 3197-3200.

LeclercQ B., rg68. Utilisation de l'huile de colza par la Poule pondeuse : son influence sur la genèse et la composition des lipides de l'œuf. C. R. Acad. Sci., 267, 2235-2237.

LECLERCQ B., I974. Contribution de l'aliment et des réserves corporelles à la genèse des lipides vitellins. Thèse Doct. Sci., Paris.

Van ITAlite T. B., Khachadurian A. K., I969. Rats enriched with odd carbon fatty acids : maintenance of liver glycogen during starvation. Nature, 165, 8I I-8 I3. 